$\mathbf{R}_{\text {ESEARCH }} \mathbf{P}_{\text {APER }} \longrightarrow \frac{\text { FOOD SCIENCE }}{\text { RESEARCH JOURNAL }}$

e ISSN-2230-9403 - Visit us :

www. researchjournal.co.in

Volume 8 | Issue 2 | October, 2017 | 375-380

DOI : $10.15740 / \mathrm{HAS} / \mathrm{FSRJ} / 8.2 / 375-380$

\title{
Nutritional status and lifestyle practices of adolescents girls (14-18 years)
}

\author{
Sanju Devi and Madhu Goyal
}

\begin{abstract}
A cross sectional study was carried out in two phases on randomly selected 300 school girls (14-18 years) studying in Government senior secondary schools of Bikaner district. An interview schedule was developed, pre tested and administered for data collection. During first phase, all subjects were assessed for their general information, anthropometric measurements and lifestyle practices. For second phase, fifty per cent $(n=150)$ of the total subjects assessed during first phase, were identified using PPS technique, to study their TEI, TEE, energy balance and correlations between different parameters. The mean BMI $\left(19.30\right.$ and $\left.19.93 \mathrm{~kg} / \mathrm{m}^{2}\right)$, WHR $(0.80 \pm .06$ and $0.79 \pm 0.06)$ and MUAC $(23.62 \pm 4.28$ and $23.99 \pm 3.71 \mathrm{~cm})$ values respectively, of 14-15 and 16-18 years of the subjects were in accordance with reference values. The lifestyle practices indicated that most of the subjects spent their leisure time on mobile/internet and watching TV. They were fond of having fast foods frequently. During second phase, TEI and TEE of the subjects was determined and as per the mean values, they fell in negative energy balance status. A positive and significant correlation co-efficient was found between TEI as well as TEE of the subjects with their BMI, WC, HC, WHR, MUAC and TEE values.
\end{abstract}

Key Words : Adolescent girls, Anthropometry, Energy balance, Lifestyle practices

How to cite this article : Devi, Sanju and Goyal, Madhu (2017). Nutritional status and lifestyle practices of adolescents girls (14-18 years). Food Sci. Res. J., 8(2): 375-380, DOI : 10.15740/HAS/FSRJ/8.2/375-380. 